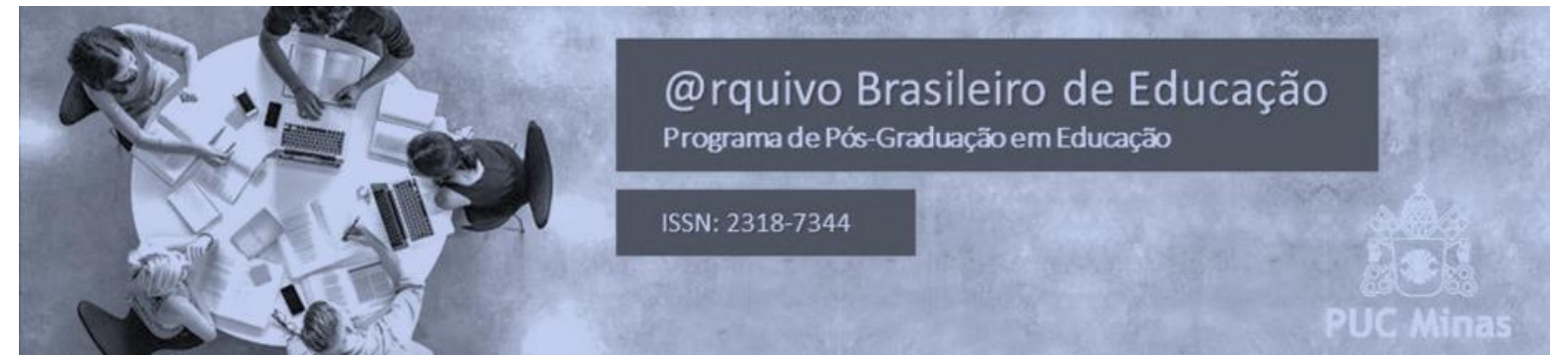

\title{
ENSINO, EPIDEMIAS E HISTÓRIA: COMO O ESTUDO HISTÓRICO TENTOU NOS ALERTAR SOBRE O ETERNO RETORNO DOS ACONTECIMENTOS
}

\section{TEACHING, EPIDEMICS AND HISTORY: HOW HISTORICAL STUDIES TRIED TO WARN US ABOUT THE ETERNAL RETURN OF EVENTS}

Giovanna de Campos Mauro Universidade Estadual de Campinas - Unicamp

Sérgio Mauro Universidade Estadual Paulista - Unesp

\section{RESUMO}

A fundação das primeiras escolas jesuítas no Brasil apenas 49 anos depois da chegada dos portugueses não impediu que a difusão do ensino, mais especificamente, do ensino de história, ocorresse de forma tardia e lenta. É de se esperar, como consequência, que o povo que vive em seu território não tenha afinidade com o estudo da disciplina iniciada por Heródoto, na Grécia Antiga. O presente artigo almeja, dessa forma, demonstrar como a falta de consciência histórica se reflete no modo brasileiro de lidar com crises mundiais e, nesse caso, com a atual pandemia causada pelo vírus COVID19. O estudo em questão se baseou na procura pelas origens da desvalorização da História, além de uma abordagem comparativa com outras sociedades. Ao final do trabalho pretende-se formular um panorama geral da situação brasileira contemporânea e refletir sobre uma possível solução para o problema.

Palavras-chave: História. Ensino. Memória. Brasil.

\section{ABSTRACT}

The foundation of the first Jesuit schools in Brazil just 49 years after the arrival of the portugueses did not prevent that the spread of the teaching, more specifically, of history teaching, take place late and slowly. As a consequence, it is to be expected that 
its people have no affinity with the study of the discipline initiated by Herodotus, in the Ancient Greece. This article aims, therefore, to demonstate how the lack of historical awareness, is reflected in the brazilian way of dealing with world crises, in this case, with the current pandemic caused by COVID-19 virus. The present study was based on the search for the origins of the lack of valorization of history, in addition to a comparative approach with other societies. At the end of the work, it is intended to formulate an overview of the contemporary Brazilian situation and reflect on a possible solution to the problem.

Keywords: History; Teaching; Memory; Brazil. 


\section{INTRODUÇÃ̃}

O presente artigo traz uma discussão sobre a importância do ensino de História e da consciência histórica, a partir da realidade vivenciada no cenário atual - a pandemia causada pelo coronavírus - e suas implicações nas soluções que as diversas sociedades estão propondo para controlar a situação.

O objetivo do estudo é analisar o ensino de História no Brasil, o qual teria sido relegado a um plano secundário durante o período colonial e que, em decorrência disso, seria, ainda hoje, precário, tardio e aristocrático. As consequências desse panorama, iniciado ainda à época do Brasil Colônia, nos eventos do presente serão discutidas ao longo do texto.

As reflexões partem da concepção dos autores que concebem a História como um evento cíclico. Além disso, a interdisciplinaridade com outras áreas das ciências humanas, como filosofia, sociologia e literatura foi utilizada para a construção desse estudo e para melhor ilustrar os seus resultados.

\section{O ENSINO TARDIO}

É de conhecimento comum que as primeiras práticas de ensino em terras brasileiras se iniciaram com os padres jesuítas. Com a sua chegada na primeira metade do século XVI, em 1549, a ordem jesuítica, mais especificamente o padre Manoel da Nóbrega, inaugurou a primeira escola (aos moldes da época) do país: o Colégio de Salvador na Bahia.

A Companhia de Jesus foi criada pelo padre Inácio de Loyola, no ano de 1534. Em todo o mundo, possuía como características únicas o caráter instrutivo e missionário. No Brasil, esteve voltada para a educação dos povos nativos e, em concomitância, à formação das primeiras aldeias no território recém descoberto. Ao contrário da atuação jesuítica na Europa, que privilegiava o combate ao protestantismo (CASIMIRO, 2007, p. 87), a função dos padres jesuítas no Brasil foi de preservar os interesses da política econômica e religiosa da metrópole sobre as colônias, sempre relacionada à escravidão, como será debatido

Os ensinamentos dos membros da Companhia de Jesus se baseavam em princípios católicos e, sendo assim, foram os responsáveis pela catequização de 
diversos grupos indígenas. Além do ensino da moral cristã de forma convencional, essas escolas, que foram denominadas, em seu conjunto, missões jesuíticas, organizavam a população em um regime que combinava trabalho e religiosidade. Os nativos submetidos a essa educação sofreram um a perda de parcela significativa de sua cultura original, devido à incorporação de certos valores europeus.

Todavia, os indígenas não foram os únicos que receberam uma educação jesuíta. Apesar de ser uma instituição com poucos anos de criação, a Companhia era muito respeitada por membros das classes mais altas. Os filhos de ricos membros das elites portuguesas eram educados pelos jesuíticos, segundo suas crenças e tradições. Para conseguir manter os privilégios decorrentes dessa proximidade com a corte portuguesa e seus habitantes no Brasil, os membros das missões se posicionaram a favor da escravidão africana, utilizando-se da justificativa de que os indivíduos provenientes dos mais diversos países da África não possuíam alma. Em relação aos indígenas, porém, a posição era diferente: eram defendidos pelos missionários, o que criava muitas vezes conflitos com os demais colonizadores, que queriam escravizá-los.

Depois de 200 anos ocupando os cargos de professores nas terras do Novo Mundo, os jesuítas são expulsos por Sebastião José de Carvalho e Melo, conhecido como Marquês de Pombal, na ocasião de sua posse do cargo de primeiro ministro no então governo do rei português João I.

Devido à essa tentativa de secularizar o ensino tanto em terras lusitanas como brasileiras, separando-o da religião, por Pombal, o grande representante do despotismo esclarecido em Portugal, são criadas instituições de ensino primário e secundário, com a contratação de professores que deveriam ser laicos. Buscando se adequar aos ideais iluministas predominantes em nível internacional no século XVIII, os currículos das escolas lusitanas e da Universidade de Coimbra sofreram reformas, buscando se adaptar às mudanças do saber científico (SILVA, 2017, p. 3). Porém, a essência do ensino luso-brasileiro continuou com fortes traços da metodologia jesuíta. No Brasil, por exemplo, os indivíduos que concorriam às vagas de professores primários no país, tinham sido submetidos a uma forte influência da ordem jesuítica. Assim sendo, o legado das Missões influenciou a cultura pedagógica que permeou a forma de ensinar existente em todo o período colonial (até 1815).

Porém, mesmo com as reformas pombalinas o Brasil permanece sem nenhuma Universidade ou Faculdade. Somente com a chegada da família real, em 1808, é que a 
necessidade de uma instituição de ensino superior ganha destaque, em uma provável tentativa de D. João VI de aproximar o seu novo lar da cultura metropolitana. No mesmo ano, é fundada a primeira faculdade do Brasil: a Escola de Cirurgia da Bahia.

Quase duas décadas depois, em 1827, são fundadas também, no Brasil então independente e sob o Império de D. Pedro I, a faculdade de Direito de São Paulo e de Olinda. Além das duas instituições de ensino superior, o Primeiro Reinado também voltou sua atenção para a ampliação da quantidade de escolas primárias existentes no país, ainda que essas fossem acessadas apenas por uma pequena e privilegiada parcela da população brasileira.

Observa-se, portanto, que a criação de instituições de ensino nas terras brasileiras, tanto primárias como de ensino superior, foi extremamente tardia em relação à europeia. Esse "atraso", se assim pode-se dizer, é decorrente do modo de pensar lusitano da época. Não era o principal interesse da metrópole portuguesa implantar uma forma de colonização que privilegiasse o ensino e as suas instituições. Enquanto países como Inglaterra, grande potência colonial e França criavam escolas e universidades nos países que colonizavam, uma vez que a educação é uma das formas mais eficientes de dominar um povo, através da imposição de sua literatura, sua história, sua língua e seus costumes, Portugal não optou por fazer o mesmo.

A colonização brasileira foi, em sua essência, de exploração visando lucros econômicos. Pouco interessava, aos portugueses, que os nativos da região e, alguns anos depois, os habitantes vindos de outros países europeus ou seus descendentes, dominassem a cultura, as tradições, a história e a produção intelectual lusa. Bastava que, através das missões jesuíticas, os índios fossem mantidos sob controle, por meio da catequização, passassem por um processo “civilizatório", ao incorporar a religião católica e trabalhassem em nome da Metrópole.

Porém, a situação não é privilégio do contexto em que o Brasil é colônia de Portugal (1500-1815). No trecho do capítulo "Bacharelo-me”, de Memória Póstumas de Brás Cubas, há um fiel retrato da situação acadêmica da elite imperial:

E foi assim que desembarquei em Lisboa e segui para Coimbra. A Universidade esperava-me com as suas matérias árduas; estudei-as muito mediocremente, e nem por isso perdi o grau de bacharel; deram-mo com a solenidade do estilo, após os anos da lei; uma bela festa que me encheu de orgulho e de saudades, - principalmente de saudades. (DE ASSIS, 1946, p. 49) 
Como se pode perceber a partir do trecho, iniciar os estudos de nível superior em uma instituição estrangeira era comum dentre os membros das classes mais altas da sociedade brasileira durante o Primeiro e o Segundo Reinado, esse último sendo o cenário da obra citada. O personagem de Machado de Assis responde a uma possível pergunta: por que não houve o interesse, por parte do governo, pela criação de um maior número de instituições de ensino superior ou ampliação das já existentes, uma vez que existiam em um número consideravelmente limitado? Simples: porque não havia demanda e, se houvesse, seria mínima. Sendo o costume de estudar de forma parcial ou total no exterior, com destaque especial para a cidade de Coimbra, devido à familiaridade com a língua e com a ex- Metrópole, difundido de maneira ampla entre os indivíduos mais abastados, como Brás Cubas, não haviam reivindicações de um maior número e uma maior valorização dessas no Brasil.

Dessa forma, se a única instituição capaz de reivindicar a criação e a valorização do ensino superior no Brasil (a elite escravocrata e latifundiária), uma vez que era a única que teria acesso à ele, não possuía interesse em fazê-lo, por qual motivo haveria de o Império se preocupar com tais questões?

\section{AS ORIGENS DO ENSINO DE HISTÓRIA NO BRASIL}

Se a fundação de escolas e faculdades sofreu com um processo de negligência que culminou na fundação de suas primeiras sedes com anos de atraso, o que dizer do currículo oferecido aos estudantes dessas instituições? Mais especificamente, da inserção do estudo da História nesses?

O Brasil possui um histórico de estudo de História demasiado recente. Ele foi inserido pela primeira vez nas grades curriculares do Colégio D. Pedro II, em 1838, ainda no Período Regencial.

E essa inserção tardia não foi isenta de consequências. A ela pode-se atribuir a relação pouco amistosa que os brasileiros, em geral, mantêm com a própria história. Sendo o estudo histórico muito recente no país, o interesse em conhecer a trajetória do país, seus grandes feitos, seus líderes, as mentalidades de seu povo e as suas origens não conseguiu ser, ainda, difundido entre a maioria da população.

A observação dos recentes acontecimentos pode sugerir que uma grande parcela dos brasileiros tem certa dificuldade, de forma generalizada, em cultivar uma memória 
(essa, parte e ferramenta da história) a longo prazo, que os impede de agir e pensar de forma coerente no presente. Em alguns casos, o indivíduo não consegue ao menos cultivar uma memória se quer, por mais curta que seja, sendo com facilidade manipulado pelos grandes veículos midiáticos de circulação de informações e por uma quantidade de notícias falsas que circulam as redes sociais.

Os reflexos da falta de memória, especialmente coletiva, não se refletem somente no cotidiano popular, mas também na própria historiografia brasileira. A existência não suficiente de um forte apreço pela história nacional, seguida de um forte sentimento de patriotismo, abre espaço para que informações falsas de amadores cheguem aos indivíduos como versão oficial dos eventos ocorridos. Os historiadores brasileiros, dessa forma, têm a tarefa de correr contra o tempo para enfrentar o pouco interesse pelo seu ofício e objeto de trabalho e impedir que a História seja distorcida por alheios.

A historiadora brasileira Laura de Mello e Souza discorre sobre essa deficiência brasileira:

\footnotetext{
Quando dizemos que tal povo não tem memória - dizemos isso frequentemente de nós mesmos, brasileiros - estamos, a meu ver, querendo dizer que não nos lembramos da nossa história, do que aconteceu, por que aconteceu, e daí escolhermos nossos representantes de modo um tanto irrefletido. (MELLO E SOUZA, 2012)
}

No caso brasileiro, tal escassez de memória e de consciência nacional tem origem, além da tardia inserção do ensino de história nas instituições, no modo como essa disciplina foi inserida.

Com uma mentalidade positivista própria do século em questão, o longo século XIX (HOBSBAWM, 2000), que regia a mente dos indivíduos, a História, junto com o Latim e o Grego, foi inserida no currículo estudantil em uma tentativa de copiar os modelos clássicos europeus de base humanística comum. Dessa forma, o Colégio D. Pedro II, importante colégio da capital do Império, buscava educar os alunos aos moldes do conhecimento considerado "clássico" à época o que, por vezes, deixava à margem estudos sobre o próprio país em que viviam, bem como seu povo ou suas origens.

Assim, esse método didático baseado em valores aristocráticos formou uma elite intelectual que enxergava o mundo a partir de um paradigma eurocêntrica e muito 
restrito, inseridos dentro de sua própria "bolha social”. Esses ex-alunos compunham, ainda, aquela pequena parcela da sociedade brasileira que ocuparia, em um futuro próximo, os principais cargos políticos do país e tomariam decisões em nome de um suposto bem para o povo. Porém, se foram educados aos moldes europeus e se não conheciam bem a própria história das mentalidades dos que vivem em seu território, como poderiam pensar em qualquer forma de solucionar os problemas daqueles para quem governavam?

A situação é pensada pelo historiador italiano Rosario Romeo que, apesar de ter pertencido a um diferente contexto, afirma: "um país idealmente separado do próprio passado é um país em crise de identidade e, portanto, potencialmente vulnerável” (ROMEO, 1995, p. 40). Assim, o atual cenário brasileiro não poderia ser muito diferente do que é, uma vez que os grupos que dominaram o governo do país nos últimos 500 anos se aproveitaram dessa vulnerabilidade para controlar as massas e se manter no poder.

O desastre supracitado poderia ser corrigido somente com uma rápida atuação dos historiadores brasileiros e da inserção correta da disciplina em muitos ambientes, como nas escolas. Porém, se sabe que a História possui, se assim pode-se dizer, um "histórico de negligência", onde sua importância é sempre considerada mínima e secundária. Esse fenômeno pode ser visto até mesmo no período regencial, onde o governo da época (a Regência Una de Araújo de Lima, no caso da inserção da disciplina no currículo do Colégio D. Pedro II, em 1838) somente viu a necessidade de sua implementação no século XIX, mais de 300 anos depois do início da colonização do país. Obviamente não se pode esperar que uma nação extremamente nova como o Brasil tenha o mesmo tempo de estudo e conhecimento históricos que os gregos ou romanos e os povos que deles descenderam. Se mesmo nos países que um dia foram considerados o berço da humanidade e, consequentemente da História como narrativa também, a disciplina é de forma constante menosprezada, pode-se supor qual é a sua situação em terras brasileiras nos dias atuais.

\section{PARA QUE SE DEVE ESTUDAR A HISTÓRIA?}

Em um país que passou a valorizar o estudo histórico (ainda que de forma mínima e não suficiente) apenas, tardiamente, nas últimas décadas, podemos 
observar, como já discutido nas linhas acima, que uma parcela significativa de seu povo, mesmo tendo condições para tal, opta por não estudar, analisar, observar, compreender e memorizar os acontecimentos do passado e do presente. Muitas vezes nós, amantes e pesquisadores da disciplina, somos questionados acerca do porquê da escolha ou existência de nossa profissão a partir da colocação da fatídica pergunta: "para que se deve estudar História?"

Essa indagação não nos foi feita no século XIX, quando o culto extremo da razão levava os pensadores da época a pensarem a História como um amontoado de conhecimentos dos quais alguns feitos mereciam mais destaques que outros. Também não foi feita no Paleolítico, período em que o recém descobrimento do fogo e a ausência da escrita impossibilitava o conhecimento do oficio do historiador por qualquer indivíduo. Ela é feita ainda hoje.

Hoje, no século XXI, depois de termos passado pela invenção da escrita, pela fundação de Mênfis como a capital do Egito, pela ascensão e queda de Roma, pelo início da expansão islâmica, pela fundação da dinastia Omíada, pela coroação de Carlos Magno como imperador do Sacro Império Romano Germânico, pela assinatura da Magna Carta por João Sem Terra, rei da Inglaterra, pela tomada de Constantinopla pelos turco-otomanos, pelo início das Grandes Navegações, pela fundação da Igreja Anglicana por Henrique VIII, pela reforma protestante de Lutero, pela revolução industrial inglesa, pela revolução francesa, pela revolução de 1830, pela primavera dos povos de 48, pelas unificações italiana e alemã, pela revolução socialista na Rússia, pela Primeira Guerra Mundial, pela Segunda Guerra Mundial, pela guerra do Vietnã, pela queda do muro de Berlim, pelo atentado de 11 de setembro e pelos tantos conflitos contemporâneos.

Mesmo depois de a História já ter mostrado que por si só já basta como motivo de estudo e indagação, ainda existem indivíduos (e não são poucos, infelizmente) que questionam sobre a necessidade e a relevância de seu estudo. Para alcançar o questionamento final do texto, motivo pelo qual o iniciamos, é preciso, como forma de contextualização, inserir no texto uma definição de História adequada.

Não a que busca dar a ela uma utilidade afirmando que é "a ciência dos homens no tempo", como fizeram os historiadores Marc Bloch e Lucien Febvre, ou que é necessária para que os erros do passado não sejam outra vez cometidos. Ou, então, a definição positivista de História, que ao reduzir o papel do homem como um mero 
coletor de informações e fatos presentes nos documentos, capazes, segundo o historiador francês Fustel de Coulanges, de fazer-se entender por si mesmos (BOURDÉ, 1983, p. 99), atribuem à disciplina um caráter de ciência pura e objetiva, que possui uma verdade única e que não requer a ação do historiador para serem entendidos.

E não porque essas estejam erradas, uma vez que não estão. Cada concepção é fruto de um diferente contexto e, logo, de diferentes mentalidades, que a concebem de modo a satisfazer seus interesses. Mas porque consideramos de maior utilidade uma definição que seja passível de compreensão tanto por parte de um leigo como de um profissional da área e que seja capaz de tocar o interior de ambos, mostrando ao primeiro por que fazemos o que fazemos e relembrando o segundo do porquê escolheu a carreira que escolheu.

Talvez a melhor maneira de definir a História nos dias de hoje seja com o auxílio da interdisciplinaridade, marca associada de historiadores como Marcel Mauss, Jacques Le Goff e Marc Bloch. É pertinente, nesse momento, ir além das definições convencionais, recorrendo, dessa forma, à nossa disciplina irmã: a literatura.

Alessandro Manzoni, escritor italiano, pertencente ao Romantismo, do século XIX, em seu livro “Os Noivos”, busca uma definição literária de História, apesar de não ser um especialista na área:

\footnotetext{
"A História pode realmente se definir como uma guerra ilustre contra o Tempo, já que, livrando de suas mãos os anos seus prisioneiros, aliás, que já foram feitos cadáveres, os chama outra vez à vida, para os passar em revista e alinhar de novo para a batalha." (MANZONI, 1987, p. 1, tradução nossa)
}

Depois de definida de forma tão profunda e poética, consideramos os problemas acerca da procura por sua utilidade já foram resolvidos. Não é pertinente questionar o historiador sobre o porquê de seu trabalho. Antes do desejo pelo conhecimento, o historiador tem o simples gosto de estudá-la (BLOCH, 1997, p. 43) e explorá-la de todas as formas possíveis. Afinal, como afirma André Gide, citado por Bloch em Apologia da

\footnotetext{
1 [No original] "L'Historia si può veramente deffinire una guerra illustre contro il Tempo, perché togliendoli di mano gl'anni suoi prigionieri, anzi già fatti cadaueri, li richiama in vita, li passa in rassegna, e li schiera di nuovo in battaglia" (MANZONI, 1987, p.1)
} 
história ou o ofício do historiador, "os jogos nos deixaram de ser permitidos”. Buscase, como fruto de uma sociedade demasiado tecnológica e especializada, uma possível utilidade para todas as tarefas. O que é impossível. O papel das ciências humanas, como um todo, não deve ser questionado buscando atribuir-lhe uma serventia. A história é necessária para o desabrochar do homo sapiens, mas por que não poderia estar, como ofício, intrínseca à felicidade do historiador?

Os impactos de ser, como somos, nós brasileiros, um povo de escassa e insuficiente consciência da própria História ou, em termos mais amplos, sem memória, são muitos. No entanto, o mais atual é a maneira de lidar com epidemias ou pandemias, como aquela com que lidamos hoje.

\section{O ETERNO RETORNO DOS ACONTECIMENTOS}

A descrença e o descrédito que os estudos históricos e seus profissionais enfrentam hoje são vários. Desde ofensas ao simples menosprezo, enfrentamos ameaças inclusive dos principais governantes do país. E todos esses fatores são refletidos no longo histórico que o Brasil tem de lidar com crises de saúde pública. Ou melhor, de não lidar.

O perceptível despreparo dos governantes federais, estaduais e municipais, assim como o alarmismo (por vezes desnecessário) crescente entre as massas são reflexos claros de como o não conhecimento ou o conhecimento insuficiente de sua própria História, tanto nacional como internacional, e da importância da mesma pode culminar em verdadeiros desastres.

As palavras do célebre historiador francês Marc Bloch não poderiam ser mais pertinentes: "a ignorância do passado não se limita a prejudicar o conhecimento do presente; ela compromete, no presente, a própria ação.” (BLOCH, 1997, p. 63). A afirmação parece um certo tipo de previsão do futuro feita por Bloch. A falta de conhecimento dos tempos remotos é, justamente, a causa do descontrole em massa que estamos vivendo hoje em relação ao novo vírus, o COVID-19.

Benedetto Croce, em La Storia come pensiero e come azione, citado pelo historiador francês Jacques Le Goff em seu livro "História e Memória”, sugere que “toda a história é história contemporânea”. Croce entende por isso que por mais afastados no tempo que pareçam os acontecimentos estudados, na realidade, a história 
liga-se às necessidades e às situações presentes nas quais esses acontecimentos têm ressonância (CROCE, 1938, p. 5). Sendo assim, segundo a interpretação de Le Goff do trecho supracitado, "a história é o conhecimento do eterno presente". (LE GOFF, 2003, p. 24)

O surto pandêmico iniciado pelo coronavírus, como também é chamado o agente patogênico, seria encarado de forma muito mais racional e adequada se o conhecimento da História e de sua concepção cíclica, como apresentada por Le Goff e Croce, fosse difundido entre uma parcela significativa da população.

Em primeiro lugar, saberíamos que os vírus vêm da mesma forma que eles vão. Eles possuem um determinado ciclo de vida, que pode ser de certa forma amenizado pelo homem, mas que terá um fim natural e inevitável. Para exemplificar o cenário, podemos utilizar o exemplo da Peste Bubônica.

Os que dominam o conhecimento da História estão (ou deveriam estar) evitando ceder ao alarmismo extremo que tomou conta de muitos no presente momento. A terrível epidemia da Peste Negra no século XIV, uma das maiores já conhecidas e enfrentadas pelo homem, que matou cerca de um terço da população europeia, acabou como resultado de sua própria dissipação. Com a diminuição do número de indivíduos, a doença acabou perdendo espaço para se propagar, além de algumas melhoras nos sistemas sanitários europeus que foram feitas ao longo dos anos e que contribuíram para a diminuição da quantidade de ratos que circulavam nas cidades medievais, transmissores da peste através das pulgas existentes em seus pelos.

Não se deve interpretar a Peste Negra, porém, como a justificativa necessária para que afirmações do tipo: "todos devemos levar nossas vidas de forma natural, como se nada estivesse acontecendo, uma vez que a pandemia irá acabar de forma espontânea e voluntariamente". Pelo contrário, a interpretação correta do exemplo e dos autores citados acima sugere que os desesperos da população do século XIV enquanto empenhavam suas ações em esforços por combater a peste foram, de certa forma, inúteis. Se os governantes pudessem ter tido um momento de lucidez e refletido de forma calma sobre as opções que tinham no momento, talvez a epidemia pudesse ter sido contida antes. Talvez. É apenas uma hipótese revisionista.

Utilizando outro exemplo mais recente fornecido pela História, esse que, por sua vez, atingiu profundamente o Brasil, é possível visualizar de forma concreta o modo 
com que os eventos históricos se repetem com frequência, ainda que a exatidão dessa, de certa forma, seja desconhecida pelos historiadores: a Gripe Espanhola.

A doença em questão provocou a que ficou conhecida como maior pandemia de toda a História, que ocorreu entre 1918 e 1919 e matou cerca de 50 a 100 milhões de pessoas. Entre os mortos, podemos citar o então presidente brasileiro, Francisco de Paula Rodrigues Alves.

A Gripe Espanhola surgiu em meados do ano de 1918 e, sendo inicialmente confundida com outras enfermidades, sua difusão ocorreu de forma rápida e silenciosa. Outros dois fatores que contribuíram para a sua propagação em níveis alarmantes foi a censura de diversos veículos de imprensa, como na Alemanha e Espanha, além das péssimas condições sanitárias em que viviam os soldados das trincheiras da Primeira Guerra Mundial.

Uma crise sanitária e um despreparo governamental que intensificam o raio de alcance de uma pandemia. É a História fornecendo aos seus personagens, mais uma vez, um exemplo de seu funcionamento cíclico, por meio do qual os eventos se repetem, de forma igual ou parecida. Contudo, não apenas a origem e o andamento da Gripe Espanhola foram verossímeis e similares a outros contextos históricos, mas também o seu fim: a influenza terminou de forma abrupta, do mesmo jeito que se iniciou.

Talvez porque os sobreviventes já haviam criado anticorpos ou talvez devido a uma mutação genética do próprio vírus. Algumas informações não são passíveis do conhecimento humano. Mas a experiência deixa um legado importante já mencionado acima: os vírus surgem com uma certa frequência indeterminada e desconhecida para nós historiadores, fazem certo estrago (alguns maiores, outros menores, mas sempre estragos) e desaparecem.

A História enquanto concepção cíclica surge com Heródoto na Grécia Antiga, mas ainda é pouco compreendida. Esse ramo dos estudos históricos é, enquanto disciplina, ainda muito discriminado no meio da academia brasileira. Prevalece, em muitas teorias e suas hipóteses, o equívoco de não perceber a atualidade, a modernidade e a permanência dos estudos da Antiguidade (ANDRADE, 2005, p. 9) no Brasil contemporâneo. Ao buscar a compreensão do presente, fatalmente se recorre aos eventos que datam de 50 ou, no máximo, 100 anos. No entanto, também a partir de uma visão ampla e panorâmica dos eventos é possível encontrar uma resposta para o que se vive hoje. 
Alguns estudiosos preferem entrar na questão metafísica e filosófica da situação, ao questionar o porquê de seres tão (supostamente) evoluídos como nós, humanos, sermos facilmente exterminados em massa por um organismo vivo acelular, de organização extremamente simples, como o vírus. O dilema é magistralmente explicado pelo filósofo Karl Popper, através da aproximação de seu método falsificacionista com as teorias darwinianas. A partir de sua teoria, pode-se interpretar que o homem, enquanto sujeito ao ambiente e à seleção realizada por esse, se encontra no mesmo patamar evolutivo de uma ameba, ou, no presente contexto, do vírus COVID-19. Nas palavras de Popper:

\begin{abstract}
A teoria do conhecimento que desejo propor é uma teoria amplamente darwiniana do crescimento do conhecimento. Desde a ameba até Einstein, o crescimento do conhecimento é sempre o mesmo: tentamos resolver nossos problemas e obter, por um processo de eliminação, algo que se aproxime da adequação em nossas soluções experimentais. (POPPER, 1979, p. 261)
\end{abstract}

A teoria evolucionista do inglês Charles Darwin foi, há muito tempo, superada por estudiosos contemporâneos, como Popper. Segundo muitas das correntes cientificistas que se apropriavam da hipótese evolucionista de Darwin, o homem estaria, em uma hipotética escala evolutiva, muito à frente dos demais seres que vivem na ecosfera. A História das pandemias sugere que é exatamente o contrário: não existe uma organização em níveis de evolução dos organismos vivos; caso contrário, o homo sapiens não encontraria a necessidade de lidar com epidemias causadas por vírus, bactérias e protozoários, uma vez que seria superior a esses e, portanto, não passível de receber seus estragos.

Todavia, as hipóteses contidas na grandiosa obra "A origem das espécies", que inauguram o pensamento darwiniano, não são de forma total descartáveis. Como explicar o diferente modo de ação dos vírus em uma mesma espécie? Tomando como referência os homo sapiens, qual seria o motivo que leva as patologias a se manifestarem de forma brutal em alguns indivíduos, de forma leve e passível de controle em outros e nem ao mesmo se manifestar em outras partes do grupo estudado?

Nas palavras de Darwin:

Todas as variações de estrutura que aparecem entre um grande número indivíduos que vivem em conjunto, quer sejam extremamente subtis quer 
sejam muito vincadas, podem ser encaradas da mesma forma que consideramos os efeitos indefinidos causados pelas condições de vida em cada organismo individual - de um modo semelhante aos efeitos de um resfriado, que afecta cada ser humano indefinidamente, consoante a sua constituição física ou o seu estado de saúde, e que pode originar tosse, gripe, reumatismo ou inflamação de diversos órgãos. (DARWIN, 2009, p. 34)

À vista disso, outro fenômeno ao qual estão sujeitas tanto as teorias evolucionistas de Darwin como a concepção cíclica da História é a aleatoriedade. Não há estudioso, tanto na área de biológicas como na de humanas, capaz de prever com total precisão onde e como uma patologia irá agir e quando irá surgir. O que sugere, portanto, que o homem convive com o eterno retorno aleatório dos eventos históricos e, com a consciência disso, poderá decidir a melhor forma de agir no presente.

Em concomitância, existem grupos, até mesmo, dentre os estudiosos, que creem em uma organização divina capaz de enviar aos grupos humanos certas epidemias, catástrofes ou pandemias, visando controlar a população mundial. Apesar de ser uma hipótese pouco científica, não pode ser de imediato desacreditada, na medida que não existe uma teoria oficial e dogmática que explique concretamente a aleatoriedade eventual dos fatos históricos. O que se pode afirmar por parte dos profissionais da História é que a disciplina merece ser ouvida atentamente. Ainda há muito que se aprender com seus ensinamentos e que podem melhorar o pensamento intelectual dos indivíduos na contemporaneidade.

\section{UMA POSSÍVEL SOLUÇÃO?}

É impossível não observar o peso que a herança negativa de um ensino tardio e aristocrático de História deixou aos brasileiros. Porém, ainda há uma chance (mesmo que remota) de superar esse legado criado pela metrópole portuguesa e de nos tornarmos um povo que, mesmo enquanto ex-colônia, usa a História, tanto a que chama os cadáveres outra vez à vida de Manzoni como a da ciência dos homens no tempo de Bloch, a seu favor. Um povo que, tendo aprendido com os erros e com as situações do passado, consegue agir melhor, já que possui a quase certa repetição dos fatos a seu lado.

A solução para atingir o patamar de uma nação que respeita a sua história nacional e a cultiva de forma cultural não será simples. Com mais de 500 anos da perpetuação da metodologia jesuítica no ensino brasileiro, certamente não será uma 
tarefa fácil reverter esse quadro e inaugurar uma forma de pensar. Contudo, esse objetivo não pode ser deixado de lado pela nova geração de historiadores que têm observado, nos últimos meses, os reflexos da pandemia de coronavírus em uma população despreparada historicamente.

Mesmo em países europeus que enfrentaram um grande histórico de conflitos e pandemias em seu território, existe, hoje, um desespero (que, em grande parte, se deve aos veículos da imprensa de divulgação de informações sensacionalistas e em massa), que acaba contribuindo para uma ainda maior propagação do vírus. Ou então, e que são ainda piores que os alarmistas, existem os negacionistas: negam a existência de uma pandemia ou a necessidade de medidas preventivas contra ela (caso exista de fato). Nesse viés, o que esperar de um país novo como Brasil? Como deveríamos lidar com a atual crise internacional, com um histórico de emergências nacionais no mínimo trinta vezes menor que o dos povos Europeus e Norte Americanos?

Mesmo com a consciência de que os historiadores jamais deveriam utilizar a conjunção "se" (DE FELICE, 1995, p. 10), ela é, nesse caso, necessária para a formulação de um juízo científico e provável. Se o território brasileiro tivesse sido colonizado sob uma educação acessível a toda a população, que buscasse a sua consciência nacional, a criação de uma memória coletiva da história narrativa do país e a iniciação ao fazer histórico, seríamos, nos dias de hoje, uma nação mais preparada, com governantes mais aptos e que não refletissem, em seus atos e pronunciamentos, os $5 \%$ da população que compõe uma elite privilegiada, mas sim a mentalidade de todos os indivíduos? Estaríamos liderando uma suposta lista imaginária de países mais aptos ao combate do novo vírus?

Outra hipótese poderia também ser colocada, embora não tenha sido o foco do presente estudo e não esteja ao nosso alcance: se o território brasileiro não tivesse sido colonizado, qual seria a sua atual situação atual e como estaria lidando com o novo vírus?

\section{CONCLUSÃO}

O estudo realizado pelo presente artigo teve como objetivo principal, refletir sobre a concepção cíclica da História, que tem sido alvo de críticas de alguns historiadores e estudiosos das ciências humanas nos últimos séculos. Além disso, 
baseando-se no método prudentemente regressivo do historiador francês Marc Bloch, o artigo procurou encontrar explicações no passado, a partir de uma visão do presente, sobre o modo como os brasileiros lidam com os diferentes problemas de caráter nacional e mundial que lhes são impostos. A hodierna crise internacional causada pelo vírus COVID-19, com origem na China, é enfrentada por cada país de uma forma diversa, não sendo considerado, para análise, no texto, qual estaria certa ou equivocada. Pudemos observar que, no Brasil, o modo de lidar com crises e emergências deve, em muito, ao histórico da educação no território, desde os primeiros anos seguintes aos contatos iniciais com os portugueses, em 1500.

Sem uma análise da trajetória do ensino no Brasil, em comparação com outros países, não seria possível chegar às conclusões sobre as raízes da curta e pouco cultivada memória coletiva de parcela da população brasileira. As consequências de três séculos como uma colônia de exploração de Portugal são observadas, claramente, até hoje, que foram objeto desse estudo.

Por outro lado, da mesma maneira que os personagens de "Diário de Um Ano da Peste", do escritor britânico Daniel Defoe, tentam desesperadamente controlar a Grande Peste de Londres, ocorrida de 1665 a 1666, com medidas absurdas e que são, na sua maioria, inúteis, os brasileiros fazem o mesmo em relação à pandemia causada pelo novo vírus, ainda que essa seja muito menos letal. Os dois grupos citados não foram/são capazes de observar que ambos os eventos são repetições de outros que já ocorreram: a peste bubônica do século XIV e a Gripe Espanhola ou o surto de H1N1, respectivamente.

Mas deve-se pensar, devido à urgência da situação, em medidas práticas, uma vez que o quadro de ensino do Brasil não pode ser alterado de forma abrupta e imediata. Por hora, o mais sábio a fazer é tomar todas as precauções necessárias e evitar, na medida do possível, agir com base no desespero. Embora o nosso histórico de relações com pandemias e crises sanitárias não seja o melhor possível, a rigor nada é ou existe, tudo devém (Platão, 1973, p. 33) e todos os momentos passam. A História mostra diariamente que esse é, assim como os demais, um acontecimento que em breve será superado (e irremediavelmente substituído por outro). 


\section{REFERÊNCIAS}

ANDRADE, Arnon de. O Estágio Supervisionado e a Práxis Docente. In: SILVA, Maria Lúcia Santos Ferreira da (Org.) Estágio curricular: contribuições para o redimensionamento de sua prática. Natal: EDUFRN Editora da UFRN, 2005.

BLOCH, Marc. As Histórias, os homens e o tempo. In. Apologia da história ou o ofício do historiador. Rio de Janeiro: Editora Zahar, 1997.

BOURDÉ; MARTIN. A escola metódica. In: As Escolas Históricas. Portugal: Publicações Europa-América, 1983, p. 99.

CASIMIRO, Ana Palmira Bittencourt Santos. Igreja, educação e escravidão no Brasil Colonial. Revista Politeia: História e Sociedade, Vitória da Conquista, v. 7. n. 1, p. 85-100, 2007.

CROCE, Benedetto. La storia come pensiero e come azione. Bari: Laterza, 1938, p. 5 .

DARWIN, Charles. A origem das espécies. Leça da Palmeira: Planeta Vivo, 2009 p. 34 .

DE ASSIS, Machado. Memórias póstumas de Brás Cubas. São Paulo: Editora Clube do Livro LTDA, 1946, p. 49.

DE FELICE, Renzo. Rosso e Nero. Milano: Baldini\&Castoldi, 1995.

DEFOE, Daniel. Um diário do ano da peste. Tradução de E. San Martin. Porto Alegre, 2002.

FABIAN, Eloi Pedro. A aproximação de Popper com a epistemologia revolucionária. Porto Alegre, 2008. Acesso em 02 abril, 2020.

FUNARI, P. P. A.; SILVA, G. J. da. Os avanços da História Antiga no Brasil. In: História Antiga: contribuições brasileiras. São Paulo: Annablume, 2008. p. 07-09.

HOBSBAWM, Eric. O longo século XIX. São Paulo: Editora Unesp, 2000.

LE GOFF, Jaques. Prefácio. In: BLOCH, Marc. Apologia da história ou o ofício do historiador. Rio de Janeiro: Jorge, 2001.

LE GOFF, Jacques. História e Memória. Campinas: Editora Unicamp, 2003, p. 24.

MANZONI, Alessandro. I Promessi Sposi. Milano: Garzanti, 1987, p. 1.

MELLO E SOUZA, Laura de. Por que estudar história? A Folha do Gragoatá, Niterói, abr. 2012. Disponível em: 
<<http://afolhadogragoata.blogspot.com/2012/o4/por-que-estudar-historia-laurade-mello_o9.html >. Acesso em: 20 fev. 2020.

PLATÃO. Teeteto. Tradução de Carlos Alberto Nunes. Pará: Universidade do Pará, 1973, p. 33 .

POPPER, K. Objective knowledge: an evolutionary approach. Oxford: Clarendon Press, 1979, p. 261.

ROMEO, Rosario. Scritti politici: 1953 - 1987. Milano: Baldini E Castoldi, 1990, p. 40.

SILVA, G. J. da; AMORIM, Simone Silveira. Apontamentos sobre a educação no Brasil Colonial (1549-1759). Interações, Campo Grande, v. 18, n. 4, p. 3, 2017.

Sobre o autor

Giovanna de Campos Mauro: Graduanda em História pela Universidade Estadual de Campinas (Unicamp). E-mail: giovannamauro@yahoo.com

Sérgio Mauro: Doutor e mestre em Letras pela USP, com pós-doutorados pela Università degli Studi di Siena, Università di Bologna e Scuola Normale Superiore di Pisa (todas da Itália). Professor-assistente aposentado na Faculdade de Ciências e Letras- campus de Araraquara - da Unesp, onde foi coordenador da área de italiano. E-mail: sergio.mauro@unesp.br 